\title{
Dentists' perception of primary health care services in family health and mother and child health clinics in Alexandria, Egypt
}

Maha El Tantawi ${ }^{1}$, Maha A. El-Din Hamza ${ }^{2}$ and Marwa M. Sabry ${ }^{3}$

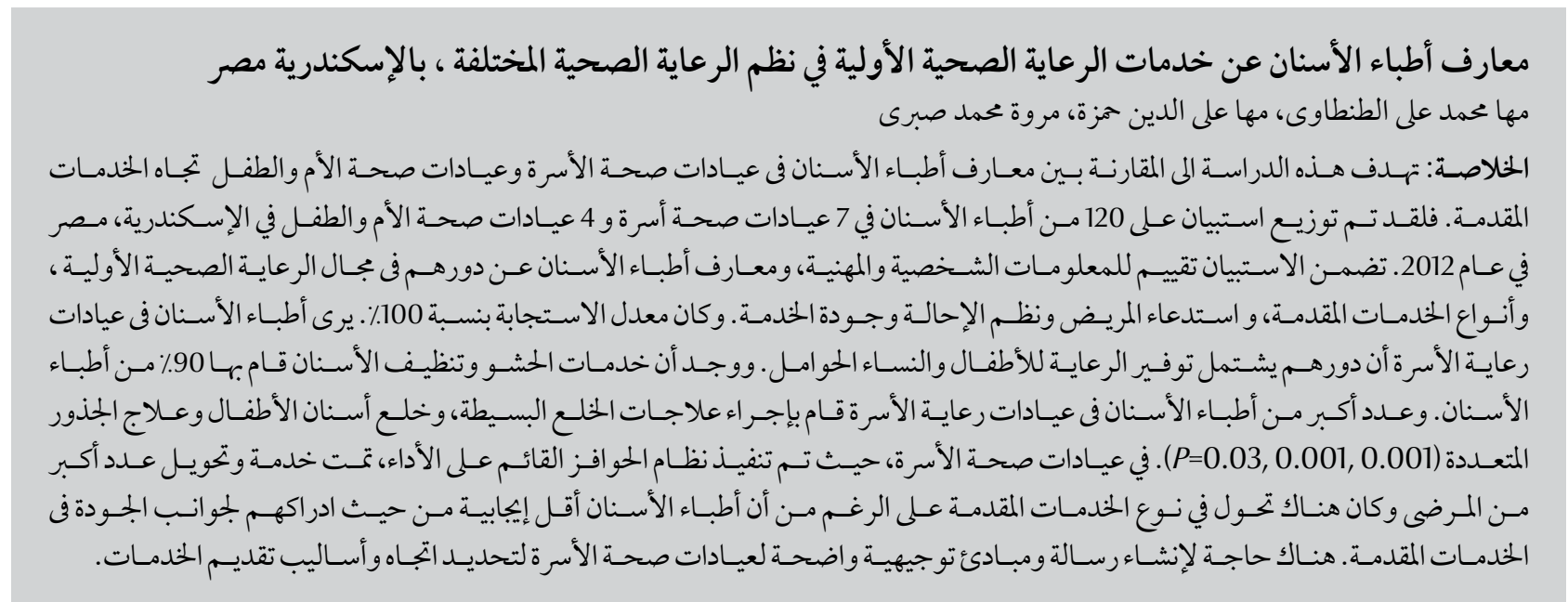

ABSTRACT This study compared dentists' perceptions of provided services in Family Health (FH) and Mother and Child Health $(\mathrm{MCH})$ clinics. A questionnaire was distributed to 120 dentists in $7 \mathrm{FH}$ and $4 \mathrm{MCH}$ clinics in Alexandria, Egypt in 2012. The questionnaire assessed personal and professional background, perceptions of primary health care (PHC) role, types of services provided, patient recall and referral systems and perception of service quality. The response rate was $100 \%$. More $\mathrm{FH}$ dentists perceived their role to include providing care for children and pregnant women. Restorations and scaling were provided by $90 \%$ of all dentists. More FH dentists reported providing simple extractions, paediatric extractions and multi-rooted endodontic treatment $(P=0.03,0.001$ and 0.001$)$. In FH clinics, where the performance-based incentive system was implemented, a greater number of patients was served and there was a shift in the type of services provided although dentists had a less positive perception of quality aspects. Thus, there is a need for the establishment of a mission and clear guidelines for the FH clinics to guide service provision.

Perception des dentistes dans les établissements de santé de la famille et de santé maternelle et infantile vis-à-vis des services de soins de santé primaires à Alexandrie (Égypte)

RÉSUMÉ La présente étude avait pour objectif de comparer la perception des dentistes travaillant dans des établissements de santé de la famille et de santé maternelle et infantile vis-à-vis des services offerts. Un questionnaire a été distribué à 120 dentistes de sept cliniques de santé de la famille et de quatre dispensaires de santé maternelle et infantile à Alexandrie (Égypte) en 2012. Ledit questionnaire évaluait l'expérience personnelle et professionnelle, les perceptions du rôle des soins de santé primaires, les types de services offerts, les systèmes de rappel des patients et d'orientation-recours, ainsi que la perception de la qualité des services. Le taux de réponse a été de $100 \%$. Davantage de dentistes des établissements de santé de la famille pensaient que leur rôle incluait la prestation de soins pour les enfants et les femmes enceintes. Les restaurations dentaires et le détartrage étaient offerts par $90 \%$ de tous les dentistes. Un plus grand nombre de dentistes en santé de la famille ont déclaré procéder à de simples extractions, à des extractions chez l'enfant et à un traitement endodontique des dents pluriradiculées ( $p=0,03,0,001$ et 0,001) . Dans les cliniques de santé de la famille, où un système d'incitation reposant sur les performances était mis en place, un plus grand nombre de patients étaient traités, bien que les dentistes aient une moins bonne perception de la qualité. Il est donc nécessaire d'organiser une mission, ainsi que de mettre au point des directives claires pour les cliniques de santé de la famille, afin d'orienter la prestation de services. 


\section{Introduction}

An essential element of primary health care (PHC) declared in the Alma Ata conference is an overall focus on prevention rather than curative service (1). Since dentistry is essentially a primary care discipline, oral health was later integrated into PHC models. The majority of patient care in dentistry occurs in community settings and involves simple procedures which are provided by general practitioners whose aim is to have a long-term relationship with patients (2). Primary oral health care includes preventive services - health education and promotion (3) - and basic treatment such as examination, bitewing radiographs, scaling and polishing, simple (1-3 surfaces) fillings and emergency relief of pain and sepsis (4).

In the past, Egypt provided PHC through various systems that sometimes had inadequate referral and integration of several programmes resulting in a fragmented system (5). A gap existed between the services $\mathrm{PHC}$ programmes intended to provide and the resources available to support them. This imbalance resulted in low salaries, lack of supplies and substandard facilities, which caused dissatisfaction among both clients and providers. Although the number of PHC units in Egypt (2.2 units per 10000 population) was among the highest in Arab countries (5), it had a small impact on health outcomes, especially among disadvantaged groups because it lacked an intersectoral approach (6).

One vertical programme operated through the mother and child health $(\mathrm{MCH})$ clinics and aimed at providing comprehensive integrated preventive, curative and rehabilitative services to mothers during and after pregnancy as well as to their newborns. In 1997, the Ministry of Health started a reform of the health system in order to provide all Egyptians with access to better quality primary and preventive services through the "Family Health Model", which combined public funds and user co-payments according to the ability to pay. In this model, integrated services were provided under the same roof for the entire family and the family physician/dentist cared for all members of the family regardless of age, gender or type of problem (7). The main features of this model were that it 1) required less time and transportation, 2) had a performance-based incentive system potentially increasing provider accountability for quality standards and reform goals and 3) had an improved referral system. Most MCH clinics, the main providers of PHC in the dental sector, were converted into family health (FH) clinics although some of them remained $\mathrm{MCH}$ clinics (8).

Sheiham and Williams in their report about reducing oral health inequalities in the Middle East (9) commented that a capitation reimbursement system would offer greater efficiency, equity and patient participation and help in continuity of care as well as patient and dentist satisfaction. Experts investigating suitable methods to finance oral health services in the Middle East recommended that oral programmes be incorporated into existing primary care programmes to reduce costs (10).

Studies were conducted to evaluate this performance-based incentive $\mathrm{FH}$ care system in the sectors of reproductive health and child care (11), diabetes management (12) and laboratory quality (13), but not in the dental sector. The present study therefore aimed to evaluate and compare the perception of dentists working in $\mathrm{MCH}$ and $\mathrm{FH}$ clinics in Alexandria, Egypt regarding the $\mathrm{PHC}$ services they provided. This evaluation will help health care policy planners to understand the impact of different financing mechanisms on health professionals and their understanding of the services they provide so that better care can be ensured.

\section{Methods}

\section{Study design, setting and sample}

A cross-sectional study was conducted among dentists working in $\mathrm{FH}$ and 4
$\mathrm{MCH}$ clinics in Alexandria, Egypt during October and November, 2012.

Approvals for the study were obtained from the Central Directorate for Research and Health Development, Ministry of Health (IRB00006877), Egypt and the Ethics of Dental Research Committee in the Faculty of Dentistry, Alexandria University.

Alexandria includes 8 administrative Ministry of Health districts with 60 primary dental care clinics (56 FH and $4 \mathrm{MCH}$ clinics). Districts where there were no $\mathrm{MCH}$ clinics were excluded leaving 3 districts included in the study. Clinics were selected in the ratio 1:2 (MCH:FH). Thus, the study covered clinics in the 3 districts of Montazah, Middle and Amreya: $2 \mathrm{MCH}$ clinics and all 3 available $\mathrm{FH}$ clinics in the Middle District and $1 \mathrm{MCH}$ clinic and $2 \mathrm{FH}$ clinics (selected randomly) in each of the 2 other districts. All dentists in these clinics were invited to participate in the study $(n=120)$. Returning the filled questionnaire was considered an implicit consent to participate in the study.

\section{Data collection}

Data were collected using a selfadministered questionnaire developed based on previous studies $(14,15)$ and pilot-tested on a sample of 15 dentists, who were not included in the study, to ensure clarity of questions. The questionnaire used close-ended questions where the respondent was asked to select the correct/appropriate answer from among several options or answer on a yes/no basis. The first section in the questionnaire asked about personal and professional background (sex, age, qualification, specialty and number of patients served in the previous year). The second section assessed respondents' perception of their $\mathrm{PHC}$ role where they were asked to select from a list of 6 roles (care of children, care of pregnant women, follow-up of schoolchildren, care of all family members, provision of low cost/free services and health education). The third section included 15 procedures that respondents were 
asked to indicate if they provided or not. In addition, they were asked if they recalled patients, referred them to other facilities, types of services these referred patients received, reasons for referral and percentage of patients referred. The last section asked respondents to indicate on a yes/no basis if they were satisfied with the availability, affordability, suitability and timeliness of services and whether they were satisfied with the services they provided and thought their patients were satisfied or not.

\section{Statistical analysis}

Data were analysed using SPSS, version 17.0. Comparison between FH and $\mathrm{MCH}$ dentists was done using the chi-squared, Fisher exact or MannWhitney $\mathrm{U}$ tests. The significance level was set at 5\%. Bar charts were used for graphical presentation.

\section{Results}

The response rate was 100\% (all 120 dentists responded; 52 and 68 from $\mathrm{FH}$ and $\mathrm{MCH}$ clinics respectively). A greater proportion of $\mathrm{MCH}$ than $\mathrm{FH}$ dentists were women $(89.7 \%$ versus $69.2 \%$ respectively, $P=0.01$ ). Most of the dentists in both types of clinic held bachelor of dentistry degrees (80.8\%) and were $<40$ years old $(60.8 \%): 31.7 \%$ were $<30$ years old, $29.2 \%$ were $30-$ $<40$ years, $22.5 \% 40-<50$ years and $16.7 \% \geq 50$ years. The differences were not statistically significant in either case. Most of the respondents were general dentists (80.3\%), followed by public health dentists (10.8\%), paediatric dentists (3.3\%) and periodontists (2.5\%). The remaining were specialists in conservative dentistry, fixed prosthodontics and oral surgery. Again the differences were not statistically significant. FH dentists served more patients than $\mathrm{MCH}$ dentists (mean 594.7 and 412.9 patients per dentist respectively) with a total of 30922 and 28075 patients served in the two types of clinics in the previous year.

More $\mathrm{FH}$ than $\mathrm{MCH}$ dentists perceived the role of $\mathrm{PHC}$ to include follow up of schoolchildren $(P=0.05)$, care of pregnant women $(P=0.05)$, care of children $(P=0.04)$, follow up of all family members $(P=0.03)$ and provision of free/low cost services $(P=0.03)$ (Figure 1). Less than $40 \%$ of dentists in both types of clinic thought PHC included providing health education $(P=0.09)$.

Figure 2 shows the services $\mathrm{FH}$ and $\mathrm{MCH}$ dentists reported they provided. Restorations and scaling were reported by $>90 \%$ of the dentists in both types of clinic. Simple extraction and health education were reported by just over $90 \%$ of $\mathrm{FH}$ dentists versus just over $70 \%$ of $\mathrm{MCH}$ dentists $(P=0.03$ and 0.09 respectively). Significantly more FH dentists than MCH dentists reported providing paediatric extractions $(P=$ $0.001)$, multi-root endodontic treatments $(P=0.001)$ and surgical extractions $(P=0.01)$. Almost half the FH dentists reported providing prosthetic services - complete $(P=0.001)$ or partial $(P=0.0001)$ dentures-compared with no $\mathrm{MCH}$ dentist reporting providing these services.

Significantly more $\mathrm{MCH}$ than FH dentists reported that they recalled patients $(86.8 \%$ versus $61.5 \%, P=0.004)$ (Table 1). Almost all dentists reported referring patients when needed. More $\mathrm{MCH}$ than FH dentists reported referring patients to receive paediatric

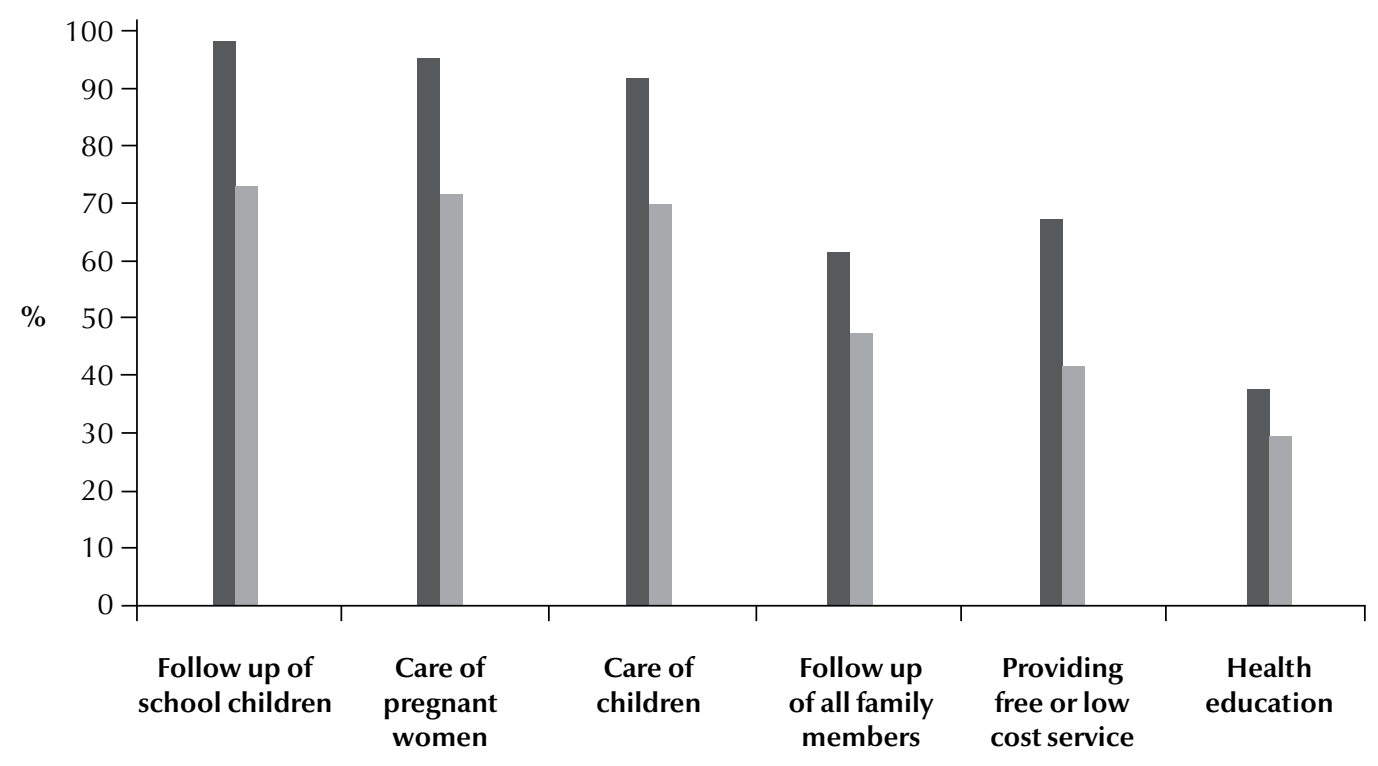

FH dentists $\mathrm{MCH}$ dentists 


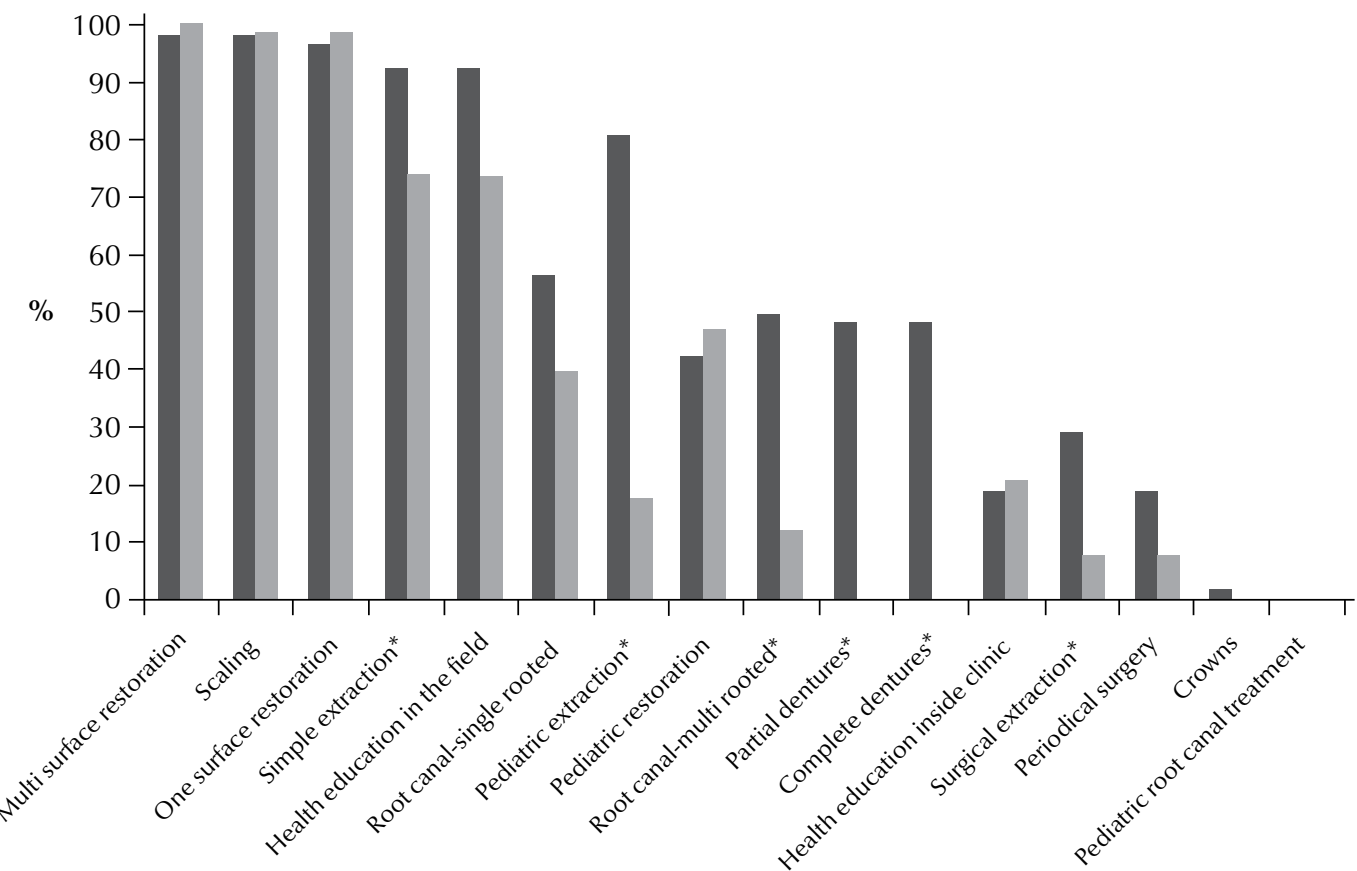

FH dentists MCH dentists

Figure 2 Dental services reported by dentists to be provided in family health (FH) and mother and child health (MCH) clinics ( ${ }^{*}$ statistically significant difference at $P \leq 0.05$ )

dental services ( $92.7 \%$ versus $42.3 \%, P$ $<0.0001)$, fixed prosthetic procedures ( $80.9 \%$ versus $46.2 \%, P<0.0001)$ and surgical procedures $(70.6 \%$ versus $36.5 \%, P<0.0001)$. FH dentists monthly referred a significantly higher per cent of their patients than $\mathrm{MCH}$ dentists (mean referred $=26.5$ and 18.5 respectively, $P<0.0001$ ). Significantly more $\mathrm{MCH}$ than $\mathrm{FH}$ dentists reported referring patients because equipment/ instruments were inadequate $(95.6 \%$ versus $76.9 \%, P=0.005)$ or dental clinics were not enough (58.8\% versus $17.7 \%, P<0.0001)$. About $50 \%$ of the dentists in both types of clinic reported they referred patients because there was no adequate professional experience to meet the patients' needs $(P=0.25)$.

Significantly more MCH than FH dentists reported that the services were available for all ( $89.7 \%$ versus $11.5 \%$, $P<0.0001)$, affordable (100\% versus $7.7 \%, P<0.0001)$ and suitable for patients' needs ( $73.5 \%$ versus $48.1 \%$, $P=0.004)$ (Table 2). MCH dentists reported that patients waited a shorter time to receive services compared to FH dentists $($ mean $=0.6$ versus 2.7 days, $P=0.001)$. More MCH than FH dentists perceived patients to be satisfied with services $(73.5 \%$ versus $42.3 \%, P$ $=0.001$ ) while more $\mathrm{FH}$ than $\mathrm{MCH}$ dentists reported they were personally satisfied with the quality of the service ( $50.0 \%$ versus $27.9 \%, P=0.01$ ).

\section{Discussion}

Few studies have focused on the assessment of PHC delivery in dentistry and dentists' perception of the services provided (16). Our study compared 2 types of PHC system (FH and $\mathrm{MCH}$ ) and the perception of dentists working within them. The perception of FH dentists of their role was more aligned with PHC concepts and they were more satisfied with the services they provided. They served and referred more patients and provided services responding to the needs of a more varied population. $\mathrm{MCH}$ dentists, on the other hand, recalled patients more frequently, and were more oriented to the quality of services and how this impacted patient satisfaction. One of the factors that may explain these differences is the newly introduced system in FH clinics that links performance to financial incentives. However, our study results are mixed and do not unequivocally show that the FH system had better perceived outcomes on quality or continuity of care than the $\mathrm{MCH}$ system.

Most of the dentists in the 2 types of clinic were women. This reflects the higher proportion of women who graduate from dental schools in Egypt in addition to the fact that male dentists are more likely to leave their jobs in the Ministry of Health because of inadequate salaries (17). A higher proportion of FH dentists were male possibly because these clinics are in remote areas where women may be reluctant to work. 


\begin{tabular}{|c|c|c|c|}
\hline \multirow[t]{2}{*}{ Recall and referral factors } & $\begin{array}{l}\text { FH dentists } \\
\qquad(n=52)\end{array}$ & $\begin{array}{l}\text { MCH dentists } \\
\quad(n=68)\end{array}$ & $P$-value \\
\hline & No. (\%) & No. (\%) & \\
\hline Recalled patients & $32(61.5)$ & $59(86.8)$ & 0.004 \\
\hline Referred patients to others & $51(98.1)$ & $68(100)$ & 0.43 \\
\hline \multicolumn{4}{|l|}{ Type of services patients are referred to receive } \\
\hline Endodontics & $49(94.2)$ & $66(97.1)$ & 0.37 \\
\hline Paediatric dentistry & $22(42.3)$ & $63(92.7)$ & $<0.0001$ \\
\hline Fixed prosthodontics & $24(46.2)$ & $55(80.9)$ & $<0.0001$ \\
\hline Surgery & $19(36.5)$ & $48(70.6)$ & $<0.0001$ \\
\hline Partial and complete dentures & $3(5.8)$ & $4(5.9)$ & 0.64 \\
\hline Other & $2(3.8)$ & $4(5.9)$ & 0.47 \\
\hline $\begin{array}{l}\text { Percentage of patients referred monthly/total number of } \\
\text { patients [Mean (SD)] }\end{array}$ & $26.5(7.3)$ & $18.5(12.4)$ & $<0.0001$ \\
\hline \multicolumn{4}{|l|}{ Reasons for referral } \\
\hline Inadequate equipment/instrument for patients' needs & $40(76.9)$ & $65(95.6)$ & 0.005 \\
\hline Inadequate professional experience for patient's needs & $28(53.8)$ & $32(47.1)$ & 0.25 \\
\hline Not enough dental clinics & $9(17.7)$ & $40(58.8)$ & $<0.0001$ \\
\hline
\end{tabular}

$P \leq 0.05$ statistically significant.

$S D=$ standard deviation .

Health education, a core PHC service, was cited by both $\mathrm{FH}$ and $\mathrm{MCH}$ dentists as the service least provided. Caring for all family members was less cited as a role than caring for mothers and children which may mean adult males and older clients are considered less of a priority for FH dentists, although they are supposed to provide care for the entire family. A gap existed among FH dentists between their perception and the reality of the situation: they considered that their role was to provide free/low cost services whereas only $7.7 \%$ thought their services were affordable. These contradictions need to be resolved by developing a mission for FH clinics that reflects the objectives of the system and the purpose for which it was developed.

Almost all FH and $\mathrm{MCH}$ dentists reported providing restorative services and scaling, the core services of dental PHC. If the number of services actually provided concurs with the dentists reporting providing these services, then there has been a shift from earlier reports of Ministry of Health services in
Egypt where extractions have been the main service provided since the 1980s (18). The greater per cent of restorative services may be explained by the population served by the clinics and the possibility that they are in urban areas. It may reflect a generalized time trend and a response to patient profile rather than a strategic shift in philosophy of the health care system. There is also the possibility that this change may be related to the performance-based incentive system. It is documented that different financing systems are

\begin{tabular}{|c|c|c|c|}
\hline Variable & $\begin{array}{l}\text { FH dentists } \\
\qquad(n=52)\end{array}$ & $\begin{array}{l}\text { MCH dentists } \\
\quad(n=68)\end{array}$ & $P$-value \\
\hline & No. (\%) & No. (\%) & \\
\hline Services are available to all levels of society & $6(11.5)$ & $61(89.7)$ & $<0.0001$ \\
\hline Cost of services are affordable by patients & $4(7.7)$ & $68(100)$ & $<0.0001$ \\
\hline Services are suitable for the needs of patients & $25(48.1)$ & $50(73.5)$ & 0.004 \\
\hline $\begin{array}{l}\text { Number of waiting days until patients receive needed services } \\
\text { [Mean (SD)] }\end{array}$ & $2.7(2.4)$ & $0.6(0.9)$ & $0.001^{*}$ \\
\hline Services provided are satisfactory to patients & $22(42.3)$ & $50(73.5)$ & 0.001 \\
\hline Dentist satisfied with quality of services & $26(50.0)$ & $19(27.9)$ & 0.01 \\
\hline
\end{tabular}

$P \leq 0.05$ statistically significant.

$S D=$ standard deviation . 
associated with changes in how dentists and patients respond to health problems (19). A study conducted in the United States of America showed that reimbursing providers increased the number of minimally invasive/preventive services offered to children (20). More FH dentists reported providing extractions (simple and surgical), possibly because they are the least expensive among the procedures FH clinics offer. The greater percentage of dentists reporting paediatric extractions in $\mathrm{FH}$ clinics reflects the absence of paediatric dentists. Workforce qualification and availability have a direct effect on oral health $(21,22)$. Endodontic treatment was reported to be provided by more FH than $\mathrm{MCH}$ dentists with wider gap in multi-root teeth. These procedures are usually expensive for the lower socioeconomic level of $\mathrm{MCH}$ patients. In addition, $\mathrm{MCH}$ patients are either young children who would be referred elsewhere for endodontic treatment or pregnant women who may not wish to have the procedure for fear it may affect their pregnancy.

More $\mathrm{MCH}$ dentists reported recalling their patients, possibly reflecting the monthly recall routine of pregnant mothers done in $\mathrm{MCH}$ clinics. The most frequently cited reason for referring patients was inadequate instruments/equipment; fewer dentists reported limited experience as the reason for referral. This agrees with a study of National Health Service dentists who reported referring difficult cases (23) and another study of New Zealand general practitioners who referred complex cases to specialists (24). A significantly higher percentage of $\mathrm{MCH}$ dentists had referred paediatric patients although there are paediatric dentists in these clinics and although most dentists perceived the follow-up of and care of children as among the roles of dental PHC. This may be explained by the fact that a greater proportion of $\mathrm{MCH}$ patients are children compared to FH patients. It may be difficult therefore for the few paediatric dentists to cover all their needs. FH dentists had referred a significantly higher number of patients in the previous month. In a PHC context, referral is a main service since $\mathrm{FH}$ providers act as gate keepers to the health care system (25). There is a need to establish clear guidelines for the FH clinics and how much their role is to act as gate keepers and provide PHC services with referral of more complex cases or if they should cover the treatment needs of all family members regardless of the complexity and cost of care. The latter approach seems unrealistic and would go against the rationale for establishing governmental tertiary care facilities. Similarly, Fayle called for a clear delineation of the duties of the United Kingdom National Health Service general dental practices and salaried dental services to establish an integrated network of services to meet patients' needs (26). Experts proposing solutions to reduce oral health inequalities in the Middle East have recommended the establishment of national systems to integrate and organize efforts by the different elements of the dental care services (9).

$\mathrm{MCH}$ dentists had a more positive perception of the availability, appropriateness, timeliness and patient satisfaction with the services they provided. However, more FH dentists reported their own satisfaction with provided services. $\mathrm{MCH}$ dentists may have a more patient-centered perspective of quality focusing on patient satisfaction as an outcome whereas FH dentists are more interested in the quantitative indicators of quality related to the number of patients they managed directly or referred. A study investigating changes after health sector reform in Suez, Egypt reported increased provider satisfaction and productivity as demonstrated by the rise of physician encounters from 3 to 16 per day (27). Another study used a case-control design to investigate the effect of a performance-based incentive system in $\mathrm{FH}$ clinics on providers' behaviour regarding the delivery of reproductive and child care services in Egypt (11). The investigators reported significant improvement in the quality of family planning, antenatal care and child care services in the clinics where the system was implemented compared to others.

Our study has some limitations. We relied on dentists' perception to compare the 2 systems which might introduce dentists' biases. Future studies are needed to complement the data of dentists' perceptions with unbiased data based on records. In addition, information from the patients' perspective would add greater depth to the comparison of the 2 models. More research is needed to follow the progress of FH towards providing dental PHC according to the Egyptian accreditation standards (28).

\section{Conclusion}

Based on our findings, dentists' perception of the quality services provided and patient satisfaction were more positive among MCH dentists. FH dentists' perception of their role was more aligned with PHC concepts although this did not necessarily translate to the actual services they provide fulfilling the same role. Based on the participants' perceptions, the FH system may be suffering from high costs which may prevent patients from utilizing services. In addition, there is a need to develop a mission for FH clinics that is aligned with the purpose for which they were established, taking into consideration the available resources.

Funding: None.

Competing interests: None declared. 


\section{References}

1. World Health Organization. Primary health care: report of the international conference on primary health care, Alma-Ata, USSR, 1978. Available at: http://apps.who.int/medicinedocs/ documents/s21370en/s21370en.pdf. accessed 22 February 2017).

2. Morris AJ, White DA, Bradnock G. Primary care: time to revise the definition? Prim Dent Care. 2000;7:93-6.

3. Honkala E. Primary oral health care. Med Princ Pract. 2014;23 Suppl 1:17-23.

4. South African Department of Health. The primary health care package for South Africa - a set of norms and standards. Department of Health, Pretoria, March 2000 (www.hsph. harvard.edu/population/vaccination/southafrica2.doc, accessed 22 February 2017).

5. Kronfol NM. Delivery of health services in Arab countries: a review. East Mediterr Health J. 2012 Dec;18(12):1229-38.

6. Rashad H. Will the Arab spring bring better health to Egyptians? Bull World Health Organ. 2011;89:786-7.

7. Jones R. Oxford Textbook of Primary Medical Care. 1st ed. Oxford: Oxford University Press; 2004. p. 84.

8. Harmeling S. Health reform in Egypt. Case study for Module 3: Reproductive health and health sector reform. Core Course on "Population, Reproductive Health and Health Sector Reform". World Bank Institute; 1999. (http://docplayer. net/24210146-Health-reform-in-egypt-case-study-for-module-3-reproductive-health-and-health-sector-reform-susanharmeling-harvard-university.html, accessed 28 February 2017).

9. Sheiham A, Williams DM. Reducing inequalities in oral health in the Africa and Middle East Region. Adv Dent Res. 2015 Jul;27(1):4-9.

10. Mumghamba EG, Joury E, Fatusi O, Ober-Oluoch J, Onigbanjo RJ, Honkala S. Capacity building and financing oral health in the African and Middle East Region. Adv Dent Res. 2015 Jul;27(1):32-42

11. Huntington D, Zaky HH, Shawky S, Fattah FA, El-Hadary E. Impact of a service provider incentive payment scheme on quality of reproductive and child-health services in Egypt. J Health Popul Nutr. 2010 Jun;28(3):273-80.

12. Youssef AA, El Mahalli AA, Akl OA, Zaghloul AA. Quality of diabetes care in primary care setting in Egypt: an example of health sector reform in developing countries. J Egypt Public Health Assoc. 2006;81:301-20.

13. Hegazy IS, Soliman L, El Ghoroury LM, Abou Zeid AH, Rakha M. Assessment of laboratory services in PHC units and first referral level hospitals in 5 governorates, Egypt 2002. Med J Cairo Univ. 2007;75:151-9.

14. Hamza MA. A study of the dental delivery system of the national health insurance organization in relation to the oral health status of insured population in the province of Alexandria [PhD Thesis]. Alexandria: Dental Public Health Department, Faculty of Dentistry, University of Alexandria; 1990
15. Ismail M, Diab M, Mansour N, Abdulmajeed AA. Pattern of referral and hospital feedback in family practice centers IsmailiaEgypt. Suez Canal Univ Med J. 2004;7:283-90.

16. Amado CF, Santos SP. Challenges for performance assessment and improvement in primary health care: The case of the Portuguese health centers. Health Policy J. 2009;91:43-56.

17. Egypt. Mobility of health professionals. Brussels: International Organization for Migration; April 2012 (http://philipus.de/ mohprof.eu/LIVE/DATA/National_reports/national_report_ Egypt.pdf, accessed 28 February 2017).

18. Zahran MA. Oral Health Situation Analysis, Egypt, 27 January to 17 February 1979. Assignment Report. Alexandria: WHO Regional Office for the Eastern Mediterranean; 1979 (EMIDENT/35, ICP/ORH/002/RB).

19. Grytten J. Models for financing dental services, a review. Community Dent Health. 2005;22(2):75-85.

20. Herndon JB, Tomar SL, Catalanotto FA, Vogel WB, Shenkman EA. The effect of Medicaid primary care provider reimbursement on access to early childhood caries preventive services. Health Serv Res. 2015 Feb;50(1):136-60.

21. Dolan TA. Professional education to meet the oral health needs of older adults and persons with disabilities. Spec Care Dentist. 2013;334(4):190-7.

22. Guarnizo-Herreno CC, Wehby GL. Dentist supply and children's oral health in the United States. Am J Public Health. 2014;104(10):e51-7.

23. Davies BJ, Macfarlane F. Clinical decision making by dentists working in the NHS General Dental Services since April 2006. Br Dent J. 2010;209(10):E17.

24. Aldawood S, Ampuan SN, Medara N, Thomson WM. Orthodontic treatment provision and referral preferences among New Zealand general dental practitioners. Aust Orthod J. 2011; 27(2):145-54

25. Berman $\mathrm{P}$, Nandakumar AK, Frere J, Salah H, El-Adawy M, Sameh El Saharty S, et al. A Reform Strategy for Primary Care in Egypt. Technical Report 9. Bethesda, MD: Partnerships for Health Reform Project, Abt Associates Inc.; 1997 (http://www. phrplus.org/Pubs/te9fin.pdf, accessed 22 February 2017).

26. Fayle S. Improving oral healthcare for children-a great opportunity. Br Dent J. 2013 Jun;214(11):547-9.

27. Gaumer G, Rafeh N. Strengthening Egypt's Health Sector Reform Program: Pilot Activities in Suez. Bethesda, MD: The Partners for Health Reformplus Project, Abt Associates Inc.; 2005 (http://pdf.usaid.gov/pdf_docs/Pnadg021.pdf, accessed 22 February 2017).

28. Standards for hospitals; Hospital, ambulatory care, and primary care standards. Cairo: Ministry of Health and Population, General Directorate of Quality, Egyptian Health Care Accreditation Organization; 2007. 